\title{
Topiramate improves neurovascular function, epidermal nerve fiber morphology, and metabolism in patients with type 2 diabetes mellitus
}

This article was published in the following Dove Press journal:

Diabetes, Metabolic Syndrome and Obesity:Targets and Therapy 6 December 2010

Number of times this article has been viewed

\author{
Amanda L Boyd \\ Patricia M Barlow \\ Gary L Pittenger \\ Kathryn F Simmons \\ Aaron IVinik
}

Department of Internal Medicine, Eastern Virginia Medical School, Norfolk, VA, USA
Correspondence: Amanda Boyd 855 West Brambleton Avenue, Norfolk, VA 23510 , USA

Tel +I 7574465912

Fax +17574465132

Email boydal@evms.edu
Purpose: To assess the effects of topiramate on C-fiber function, nerve fiber morphology, and metabolism (including insulin sensitivity, obesity, and dyslipidemia) in type 2 diabetes.

Patients and methods: We conducted an 18-week, open-label trial treating patients with topiramate. Twenty subjects with type 2 diabetes and neuropathy $(61.5 \pm 1.29$ years; 15 male, 5 female) were enrolled and completed the trial. Neuropathy was evaluated by total neuropathy scores, nerve conduction studies, quantitative sensory tests, laser Doppler skin blood flow, and intraepidermal nerve fibers in skin biopsies.

Results: Topiramate treatment improved symptoms compatible with C-fiber dysfunction. Weight, blood pressure, and hemoglobin $\mathrm{A}_{1 \mathrm{c}}$ also improved. Laser Doppler skin blood flow improved significantly after 12 weeks of treatment, but returned to baseline at 18 weeks. After 18 weeks of treatment there was a significant increase in intraepidermal nerve fiber length at the forearm, thigh, and proximal leg. Intraepidermal nerve fiber density was significantly increased by topiramate in the proximal leg.

Conclusion: This study is the first to demonstrate that it is possible to induce skin intraepidermal nerve fiber regeneration accompanied by enhancement of neurovascular function, translating into improved symptoms as well as sensory nerve function. The simultaneous improvement of selective metabolic indices may play a role in this effect, but this remains to be determined.

Keywords: diabetic neuropathy, skin blood flow, skin biopsy, diabetes

\section{Introduction}

The leading cause of nontraumatic extremity amputation is complications of diabetes, with over 96,000 amputations per year. ${ }^{1}$ Neuropathy associated with diabetes predisposes to pain, numbness, ulceration, infection, gangrene, and amputation. Somatic and autonomic diabetic neuropathy contribute to $87 \%$ of these amputations. ${ }^{2}$ It is now appreciated that there are different forms of neuropathy in diabetes. ${ }^{1}$ Damage occurs to both large, myelinated nerve fibers and small, unmyelinated fibers (C-fibers). The small, unmyelinated $\mathrm{C}$-fibers subserve thermal and pain perception, and the small autonomic fibers affect sweating and vascular control. ${ }^{3}$ Damage to small, unmyelinated C-fibers has the greatest impact on survival and quality of life, producing initial symptoms such as pain, numbness, and anhidrotic skin with disordered skin blood flow (SKBF) predisposing to foot ulcers, infection, gangrene and limb loss. ${ }^{4}$ Diabetic peripheral neuropathy is the primary cause of diabetic ulcers and the most predictive diagnosis for an eventual amputation. Current therapies for diabetic peripheral neuropathy are for symptomatic relief of pain and not for the underlying disorder. ${ }^{5-8}$ Any addition to the therapeutic armamentarium would be welcome. 
It has been shown that small fiber neuropathies are quantifiable with newer tests of $\mathrm{C}$-fiber integrity that include quantitative measures of SKBF and corneal confocal microscopy, ${ }^{9-11}$ quantification of intraepidermal nerve fibers (IENF), ${ }^{12-16}$ and quantitative sensory testing (QST) ${ }^{17}$ Heat-induced vasodilation $\left(44^{\circ} \mathrm{C}\right)$, is reduced in subjects with impaired glucose tolerance, and in type 2 diabetic patients with and without neuropathy. ${ }^{18}$

We have reported that one of the earliest quantitative sensory abnormalities found in people with diabetic peripheral neuropathy is the impairment of small fiber sensory perception that cosegregates with disordered neurovascular function. ${ }^{19,20}$ Furthermore, there is evidence to suggest that one of the early manifestations of C-fiber dysfunction can be based upon skin biopsies, with measurement of the density of thin, unmyelinated nerve fibers using immunohistochemistry for Protein Gene Product 9.5 (PGP-9.5) as a neuronal marker. ${ }^{12,13,15,16,21,22}$ Since description of the utility of PGP9.5 as a marker for IENF in human skin, ${ }^{23}$ it has been used for identification of small nerve fibers in the dermis and epidermis in a range of small fiber neuropathies, including human immunodeficiency virus, and idiopathic small fiber and postherpetic neuralgia, among others. ${ }^{13,15,24-29}$ In addition, we have now established that there are characteristic changes in IENF that distinguish the metabolic syndrome from diabetes. ${ }^{30}$ IENF density was recently given a level A recommendation by the European Federation of the Neurological Societies and the Peripheral Nerve Society as a reliable and efficient technique to confirm the clinical diagnosis of small fiber neuropathy. ${ }^{31}$ The IENF density has been shown to correlate inversely with cold and heat detection thresholds. ${ }^{32} \mathrm{~A}$ oneyear diet and exercise intervention program in patients with small fiber neuropathy and impaired glucose tolerance led to increased IENF density. ${ }^{33}$ IENF loss is evident early in the disease process, declines with increasing neuropathic pain, and can be used as an outcome measure in clinical trials..$^{31,33}$ Apart from the one-year trial on diet and exercise, ${ }^{33}$ no drug has been shown to induce $\mathrm{C}$-fiber regeneration.

Topiramate, a structurally novel antiepileptic drug, is effective in treatment of various types of epilepsy and prevention of migraine headaches. A sulfamate-substituted derivative of $d$-fructose, topiramate has several pharmacologic properties suggesting it may have potential for overcoming the programmed cell death implicated in the pathogenesis of neuropathy. ${ }^{4}$ It enhances gamma aminobutyric acid (GABA) activity by interacting with a nonbenzodiazepine site on GABA receptors, has negative modulatory effects on voltage-activated $\mathrm{Na}+$ channels,${ }^{34}$ selectively blocks
AMPA/kainate glutamate receptors, has negative modulatory effects on L-type high voltage-activated $\mathrm{Ca}^{2+}$ channels,${ }^{35}$ and inhibits the carbonic anhydrase isozymes, CA-I and CA-II. ${ }^{34}$ These multiple mechanisms of action may contribute to its anticonvulsive, antinociceptive, and putative neuroprotective properties. There has been no report on the ability of topiramate to influence the structure and function of IENF, although there are animal studies to suggest that it may exercise these properties. ${ }^{36,37}$

Topiramate thus clearly offers an advantage over agents currently used for neuropathy in as much as it relieves pain and, in animal studies, is neurotrophic and neuroprotective, and may have beneficial effects on weight, blood pressure, and lipids. The American Diabetes Association and the American Society of Pain have recently added topiramate and other anticonvulsant medications to the diabetic neuropathy treatment regimen. ${ }^{38}$ There may be an added benefit with topiramate in treating diabetic patients with neuropathy, because it exerts both neurotrophic and metabolic effects that have not been shown by other anticonvulsants. $7,8,39$

We have reported on pain reduction with topiramate ${ }^{7}$ which persisted for at least six months ${ }^{40}$ and had salutary effects on weight, blood pressure, and serum lipids. The aim of this study was to determine whether topiramate induces regeneration of small cutaneous nerve fibers in concert with improved SKBF and sensory measures of C-fiber function.

\section{Material and methods}

Twenty subjects were recruited and completed the study. The Eastern Virginia Medical School Institutional Review Board approved the study and all subjects gave written informed consent prior to any study procedures. All subjects participating in this study had type 2 diabetes, were aged 35-75 years, and had documented evidence of diabetic peripheral neuropathy. Their baseline demographic and clinical data are shown in Table 1. The study was a pure within-subject repeated-measure design comparing skin biopsy data, sensory responses, and SKBF before and after treatment with topiramate in subjects with diabetic peripheral neuropathy. All assessments occurred once prior to treatment and again at the end of the 18-week treatment period. In addition, SKBF testing was performed at week 12. After initial evaluation, all patients received active treatment with topiramate.

\section{Quantitative neuropathy testing}

All patients had a complete history, and a physical and neurologic examination. Neurologic symptom scores and 
Table I Baseline clinical and demographic data $(n=20)$

\begin{tabular}{|c|c|}
\hline Variable & Mean \pm SEM \\
\hline Age (years) & $61.5 \pm 1.3$ \\
\hline Race (W:B:A) & $16: 3: 1$ \\
\hline Gender (male:female) & $15: 5$ \\
\hline Height (inches) & $70 \pm 0.9$ \\
\hline Weight (lbs) & $228 \pm 11.9$ \\
\hline BMI $\left(\mathrm{kg} / \mathrm{m}^{2}\right)$ & $32.5 \pm 1.2$ (normal I8.5-24.9) \\
\hline $\begin{array}{l}\text { Waist circumference } \\
\text { (inches) }\end{array}$ & $44.5 \pm 1.5$ \\
\hline Systolic BP (mmHg) & $\mathrm{I} 42 \pm 4 . \mathrm{I}$ (goal $<130 \mathrm{mmHg}$ in diabetes) \\
\hline Diastolic BP (mmHg) & $8 \mathrm{I} \pm 1.9$ (goal $<90 \mathrm{mmHg}$ in diabetes) \\
\hline Pulse (beats per minute) & $81 \pm 3.9$ \\
\hline $\begin{array}{l}\text { Fasting serum glucose } \\
(\mathrm{mg} / \mathrm{dL})\end{array}$ & $135 \pm 7.6($ normal <99) \\
\hline $\mathrm{HbA}_{\mathrm{Ic}}(\%)$ & $7.4 \pm 0.3$ (goal $<7$ in diabetes) \\
\hline Total cholesterol mg/dL & $175 \pm 9.7$ (normal <200) \\
\hline LDL mg/dL & $94 \pm 7$ (normal $<100)$ \\
\hline $\mathrm{HDL} \mathrm{mg} / \mathrm{dL}$ & $46 \pm 3$ (normal male $>40$, female $>50)$ \\
\hline Triglyceride mg/dL & $176 \pm 27($ normal $<\mid 50)$ \\
\hline $\begin{array}{l}\text { Total neuropathy score } \\
\text { (scored bilaterally) }\end{array}$ & $3 I . I \pm I 5.5($ normal $<6$, severe $>40)$ \\
\hline Cool detection threshold & $9 \pm 2\left(\right.$ normal $\left.3.0 \pm 1.0^{\circ} \mathrm{C}\right)$ \\
\hline $\begin{array}{l}\text { Warm detection } \\
\text { threshold }\end{array}$ & $\mathrm{II} \pm \mathrm{I}\left(\right.$ normal $\left.7.8 \pm \mathrm{I} .0^{\circ} \mathrm{C}\right)$ \\
\hline Monofilament threshold & $5 \pm 0.1$ (normal $3.9 \pm 0.2 \log g)$ \\
\hline Vibration perception & $5.4 \pm 2($ normal 0$)$ \\
\hline
\end{tabular}

Abbreviations: LDL, low-density lipoprotein; HDL, high-density lipoprotein; SEM, standard error of mean; HbAlc, glycosylated hemoglobin.

neurologic disability scores were generated by completion of a questionnaire modified from Dyck. ${ }^{41}$ The sum of the three scores (symptom, motor, and sensory scores) is the total neuropathy score. Neuropathy was established by the criteria suggested by the American Diabetes Association and American Academy of Neurology. ${ }^{42}$ QST included measures of temperature and touch perception thresholds. Quantitative autonomic function was assessed by three tests, ie, heart rate variability during deep breathing at six breaths per minute ( $E: I$ ratio), the $R: R$ variation in response to the Valsalva maneuver, and the $\mathrm{R}: \mathrm{R}$ variation is response to postural change as suggested by the neurologic disability score position statement on neuropathy. ${ }^{38}$

QST was performed using the Medoc device (TSA2001/ VSA3001) following previously published procedures. Touch pressure was measured using graded monofilaments (Semmes-Weinstein). ${ }^{17}$ Measurements were taken $2 \mathrm{~cm}$ proximal to the skin biopsy sites on the nondominant limbs.

Nerve conduction studies were performed on the nondominant peroneal motor, sural sensory, and ulnar motor and sensory nerves, using standard techniques of supramaximal percutaneous nerve stimulation, surface recording, and appropriate filtering and signal amplification. Stimulation-to-recording electrode distances, electrode placement, and limb surface temperatures were defined for each nerve conduction study to ensure that all studies were performed under similar conditions.

\section{Skin blood flow}

SKBF was measured by continuous laser Doppler assessment of the response to varying stimuli, as previously described. ${ }^{20,43}$ Testing was done on the nondominant foot and proximal calf at baseline, after six weeks of maintenance treatment (ie, a total of 12 weeks' treatment) and at the end of 12 weeks of maintenance treatment. The SKBF and temperature probes were placed over the external aspect of the nondominant leg $10 \mathrm{~cm}$ below the knee over the area where the skin biopsy sample was taken and on the dorsum of the foot. SKBF examinations were done with the patient in a reclined position with the legs elevated and completely extended. After a 10-minute baseline period, the temperature was increased to $32^{\circ} \mathrm{C}$ for 10 minutes, $40^{\circ} \mathrm{C}$ for 10 minutes, and then to $44^{\circ} \mathrm{C}$ for 20 minutes.

\section{Skin biopsy}

Skin punch biopsies $(3 \mathrm{~mm})$ were performed under local anesthesia. Biopsies were collected from each patient's dorsal forearm, lateral thigh (10 $\mathrm{cm}$ proximal to patella), lateral proximal leg (10 cm distal to fibular head), and lateral distal leg (10 cm proximal to lateral malleolus). Tissue samples were immediately fixed in $2 \%$ buffered paraformaldehyde/ lysine/periodate solution for $12-24$ hours at $4^{\circ} \mathrm{C}$. They were subsequently cryoprotected in phosphate buffer with $20 \%$ glycerol overnight and frozen for later cryosectioning.

Procedures for identifying neurons in skin biopsies employed immunofluorescence techniques in a modification of the protocol described by McCarthy et al. ${ }^{13}$ The processing and cutting of the slides were done following procedures previously described. ${ }^{30}$ The skin biopsy data from this cohort of patients was also compared with healthy control patients taken from the large skin biopsy database created and maintained at our institute.

\section{Fasting blood chemistries}

Blood samples were obtained at the screening and final visits for determination of glycosylated hemoglobin $\left(\mathrm{HbA}_{1 \mathrm{c}}\right)$, lipid profile including total serum cholesterol, high-density lipoprotein (HDL) cholesterol, low-density lipoprotein (LDL) cholesterol, free fatty acids, and triglycerides, and fasting serum glucose and C-peptide. We also measured serum B12 and rapid plasma reagin at screening in order to rule out occult neuropathies. In addition, liver enzymes were measured at screening, and at weeks 4, 6, 12, and 18 . 


\section{Statistical analysis}

The primary endpoints were SKBF, QST, and indices of IENF density and length, all of which are continuous (parametric) data. The independent variable was topiramate treatment. Repeated measures analysis of variance was used to examine the treatment effects for SKBF, QST, and skin biopsies. Significant differences were accepted as $P<0.05$. Where significant treatment differences were observed, contrast testing was used to determine the significance at each level, while allowing for multiplicity of comparisons. In addition, nonparametric Spearman rank correlations were done to examine the relationship between IENF, SKBF, and measures of neurologic function.

\section{Results}

The patients entered into this study were predominantly Caucasian, overweight, male, and hypertensive type 2 diabetics with clinical evidence of distal symmetric polyneuropathy (Table 1). Our previous experience prescribing topiramate led us to use a low starting dosage and a slow dosage-escalation protocol. Oral topiramate was administered initially at a dose of $25 \mathrm{mg}$ /day and gradually titrated over six weeks to a dose of $100 \mathrm{mg} /$ day or the maximum tolerated dose. Fifteen of the 20 subjects were able to tolerate $100 \mathrm{mg} /$ day, two subjects were maintained on $75 \mathrm{mg} /$ day, and three were on $50 \mathrm{mg} /$ day. A 12-week maintenance period followed the titration phase. During this period, the dose of study medication remained constant. One of the 20 patients was discontinued from the study early due to cognitive effects of the medication, including psychomotor slowing, word finding difficulty, and fatigue. All other patients tolerated their maximally titrated dose with little cognitive effect.

We have previously reported ${ }^{16}$ that mean dendritic length and IENF density progressively decreased from proximal to distal sites in patients with neuropathy. In this cohort of patients, there was a similar decrease in IENF density and mean dendritic length from proximal to distal sites (Figure 1a and 1b). Nerve fiber density in skin taken from patients before topiramate treatment was significantly lower than in skin taken from comparable sites in healthy control patients in our large skin biopsy database. Comparing the results at each site, IENF density in the forearm was significantly lower in patients $(13.2 \pm 3.5)$ compared with controls $(32.9 \pm 3.2 ; P<0.001)$. Similar deficits in IENF were seen in the thigh $(8.4 \pm 5.7$ versus $35.6 \pm 7.3 ; P<0.01)$, proximal leg $(3.1 \pm 2.2$ versus $17.4 \pm 2.0 ; P<0.001)$, and distal leg (4.6 \pm 4.6 versus $28.0 \pm 3.9 ; P<0.001)$.

Mean dendritic length of nerve fibers in skin from controls was similar, regardless of site, ie, forearm $(3.28 \pm 0.18 \mu \mathrm{m})$, thigh $(3.69 \pm 0.3 \mu \mathrm{m})$, proximal leg $(3.34 \pm 0.23 \mu \mathrm{m})$, and distal leg $(3.31 \pm 0.3 \mu \mathrm{m})$. There was a progressive shortening of fibers in patients before treatment with topiramate from forearm to distal leg. In addition, mean dendritic length in skin from patients before topiramate treatment was significantly lower than skin taken from comparable sites in control subjects, ie, thigh $(2.28 \pm 0.23 ; P<0.001)$, proximal leg $(1.79 \pm 0.26 ; P<0.001)$, and distal leg $(1.94 \pm 0.35$; $P<0.005)$. Mean dendritic length was not different from controls in the forearm $(2.86 \pm 0.19 ; P>0.05)$.

Treatment with topiramate significantly increased mean dendritic length in the forearm and proximal leg (Figure 1a) and IENF density in the proximal leg (Figure 1b). A representative sample is shown in Figure 2. This was associated with improvement in total neuropathy scores, including touch, vibration, and prickling pain thresholds, and reduction in weight, body mass index, systolic and diastolic blood pressures, and $\mathrm{HbA}_{1 \mathrm{c}}$ (Table 2). SKBF was measured at baseline, 12 weeks, and 18 weeks. A significant increase in SKBF was seen at week 12, but returned to baseline at week 18. SKBF in the leg increased from $87.7 \pm 0.1$ to $101.3 \pm 0.1(P<0.001)$
A

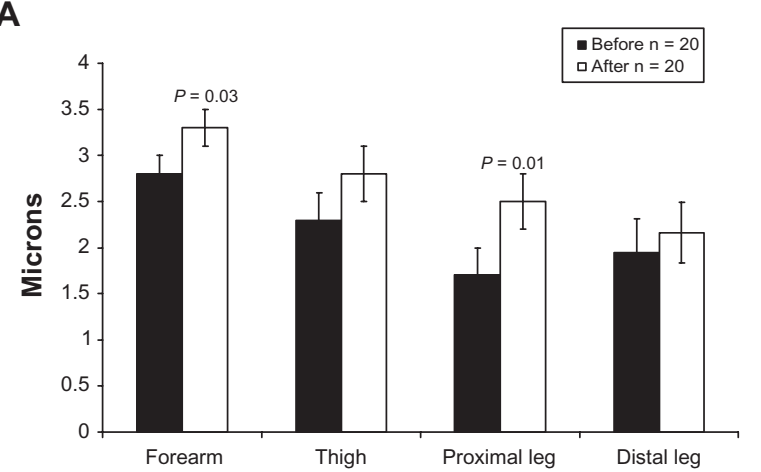

B

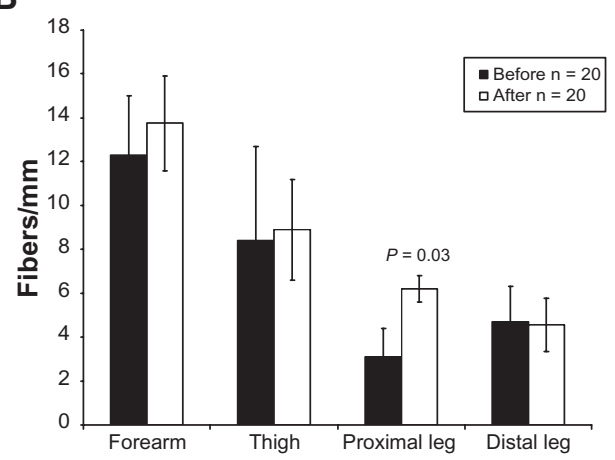

Figure I A) Mean \pm SE dendritic length (Microns) at 4 sites before and after 18 weeks of topiramate treatment. Significant differences (ANOVA) are shown. B) Mean \pm SE nerve fiber density (Fibers $/ \mathrm{mm}$ ) in skin at different sites before and after 18 weeks of topiramate treatment. A significant change was only found in proximal leg. 

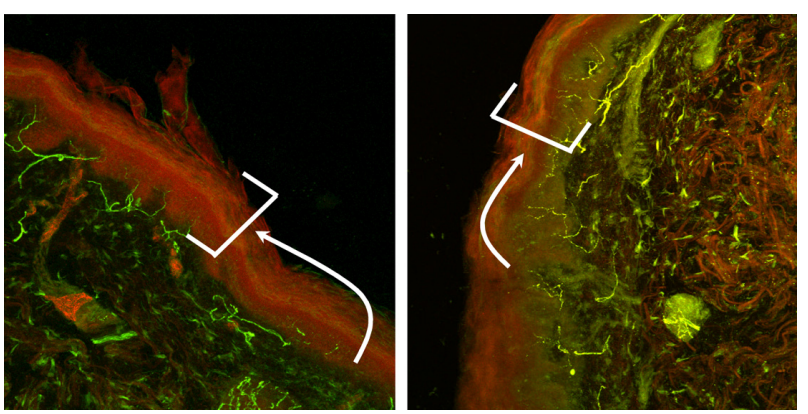

Figure 2 A skin biopsy sample before and after treatment with topiramate shows an increase in the intraepidermal nerve fiber density (epidermis indicated by box at arrow) and dendritic length after treatment.

and in the foot from $102.6 \pm 0.2$ to $143.7 \pm 0.6(P<0.001)$ laser Doppler units at 12 weeks. No correlations were found between the changes in measures of neurologic function, IENF, and the changes in metabolic parameters.

\section{Conclusion}

In this small within-subject pilot study, we have shown that 18 weeks of treatment with topiramate induced improvement in neurologic disability scores, including prickling, vibration, and touch perception. This was associated with improvement in SKBF after 12 weeks of treatment, but this returned to baseline at 18 weeks. Quantification of IENF density and mean dendritic length in skin biopsies, carried out at entry into the study and repeated at the same sites after 18 weeks of treatment, showed an increase in nerve fiber length at the forearm and proximal leg after treatment with topiramate, and an increase in nerve fiber density at the proximal leg.

We have previously shown ${ }^{4,44}$ that the earliest change found in patients with the metabolic syndrome without hyperglycemia is a reduction in mean dendritic length and that the

Table 2 Variables with significant changes from baseline to 18 weeks post-initiation of treatment with topiramate

\begin{tabular}{|c|c|c|c|}
\hline Variable & $\begin{array}{l}\text { Baseline } \\
\text { (pre) }\end{array}$ & $\begin{array}{l}\text { I8 weeks } \\
\text { (post) }\end{array}$ & Significance \\
\hline Weight (lb) & $228 \pm 11.9$ & $220 \pm 12.3$ & $P<0.000$ I \\
\hline $\mathrm{BMI}$ & $32.5 \pm 1.2$ & $31.3 \pm 1.3$ & $P<0.001$ \\
\hline Diastolic BP (mmHg) & $81 \pm 1.9$ & $71 \pm 1.6$ & $P<0.0001$ \\
\hline Systolic BP (mmHg) & $143 \pm 4.1$ & $122 \pm 3.1$ & $P<0.0001$ \\
\hline $\mathrm{HbA}_{\mathrm{lc}}(\%)$ & $7.4 \pm 0.31$ & $6.8 \pm 0.20$ & $P<0.0001$ \\
\hline $\begin{array}{l}\text { Total neuropathy score } \\
\text { (normal }<6 \text {, severe }>40 \text { ) }\end{array}$ & $31.1 \pm 15.5$ & $21.0 \pm 11.5$ & $P=0.0026$ \\
\hline Touch threshold & $2.7 \pm 3.1$ & $0.45 \pm 1.4$ & $P=0.004$ \\
\hline Prickling threshold & $4.3 \pm 2.1$ & $2.1 \pm 2.4$ & $P=0.0008$ \\
\hline Vibration threshold & $5.4 \pm 2.3$ & $4.4 \pm 2.2$ & $P=0.039$ \\
\hline
\end{tabular}

Abbreviations: $B M I$, body mass index; $B P$, blood pressure; $\mathrm{HbA}_{1 \mathrm{c}}$, hemoglobin $A_{1 \mathrm{c}}$. decrease in IENF density occurs after at least five years of diabetes and is most prominent at the distal site. ${ }^{44}$ Thus, the patients in this study most closely resemble those with diabetes, including those with features of the current definition of the metabolic syndrome (Table 1).

There is a distinct clinical entity of neuropathy associated with the metabolic syndrome in the absence of glucose intolerance. However, up to $50 \%$ of patients with painful neuropathy may have impaired glucose tolerance. ${ }^{17,45,46}$ This suggests that treatment of the nonhyperglycemic components of the metabolic syndrome may be important. While we do show an improvement in $\mathrm{HbA}_{1 \mathrm{c}}$, blood pressure, and weight similar to that reported for topiramate in previous neuropathy studies, ${ }^{7,39}$ we could not find correlations between changes in nerve fibers or cognitive function and changes in the metabolic parameters.

In this study we showed that 18 weeks of treatment with topiramate improves total neuropathy scores, touch, prickling pain, and vibration perception, as well as IENF. We have reported ${ }^{16,44}$ that distal leg IENF density showed significant negative correlations with warm $(P<0.02)$ and cold $(P<0.05)$ thermal threshold, heat pain $(P<0.05)$, pressure sense $(P<0.05)$, sensory score $(P<0.03)$, and total neuropathy score $(P<0.03)$, and thus objective measures are likely to be related. It is not clear, at this point in time, if these changes can be sustained for greater periods. It has been shown that pain improvement persists for at least six months, ${ }^{40}$ and anecdotally our patients appeared to continue to improve beyond the defined study period. Clearly, longer duration studies are needed to determine if the cross-sectional correlates of nerve fiber densities and mean dendritic length with different sensory modalities can be realized.

We have reported that there is a direct correlation between distal leg IENF density and duration of diabetes, ${ }^{47}$ suggesting that there is a loss of about one nerve fiber per $\mathrm{mm}$ per year. A reduction of one nerve fiber per $\mathrm{mm}$ translates into clinically significant changes in total neuropathy scores and objective measures of cognitive function. Furthermore, an improvement in the proximal leg of three nerve fibers per $\mathrm{mm}$ was found to provide clinically meaningful changes in objective parameters of nerve function. Therefore, we would propose that a conservative estimate of double the value for change in function, ie, two nerve fibers per mm, could be considered a minimal requirement for success in future studies of agents affecting nerve biology. Furthermore, we have also reported that there is a progressive shortening of the mean dendritic length in the distal leg. ${ }^{47}$ Since this 
change occurs in the metabolic syndrome independent of blood glucose, ${ }^{44}$ it seems that this could be a valuable endpoint in patients being treated for components of the metabolic syndrome other than hyperglycemia. The pattern of regeneration is unique and dictates a need to use IENF length, rather than density, as an endpoint in clinical studies at sites where viable nerve fibers still exist.

Because of the demonstrated effects of topiramate on various metabolic aspects, it could be an important addition to therapies aimed at the metabolic syndrome and its sequelae, including neuropathy and diabetes. Topiramate has been reported to have positive effects on pain relief in diabetic peripheral neuropathy, ${ }^{7}$ an effect which has been shown to be durable ${ }^{40}$ in clinical trials for the management of diabetic peripheral neuropathy pain syndromes. In these studies it was noted that weight loss and changes in metabolic parameters accompanied pain relief, but the role of topiramate in disease modification of neuropathy is limited..$^{48}$ Although the mechanisms underlying the neuroprotective effect of topiramate are not fully understood, there may be added benefits for people with type 2 diabetes. Topiramate inhibits weight gain in animals on a high-fat diet, but the mechanism through which change in energy balance is achieved is unclear. ${ }^{49}$ Topiramate causes weight $l o s s^{50}$ sustained for one year..$^{51}$ In our studies, treatment with topiramate not only improved symptoms of neuropathy, but also reduced body weight, body mass index, systolic and diastolic blood pressure, and $\mathrm{HbA}_{1 \mathrm{c}}$. These findings are not unlike those previously reported with topiramate treatment in normal healthy patients, as well as in patients with diabetes..$^{50,51}$

The caveats, however, are that this was a small open-label trial, with careful attention paid to minimizing the untoward side effects known to occur at higher doses of topiramate. Effects of topiramate on cognitive function, including psychomotor slowing, short-term memory loss, fatigue, and anorexia have been reported with topiramate treatment. These common side effects make it difficult to design a true placebo-controlled trial. In our short study, we found if there was a low starting dose $(15 \mathrm{mg})$, and a slow taper to a low maximum dose of $100 \mathrm{mg}$, many of these side effects are mitigated. What would be attractive is the discovery of an agent with the beneficial neurologic and metabolic effects of topiramate, but free of cognitive dysfunction and intensive dosing requirements, which would allow a true placebocontrolled trial to be performed.

\section{Disclosure}

The authors report no conflicts of interest in this work. This was an inhouse study with no outside funding source.

\section{References}

1. Vinik A, Pittenger G, McNitt P, Stansberry KB. Diabetic neuropathies: An overview of clinical aspects, pathogenesis, and treatment. In: LeRoith D, Taylor SI, Olefsky JM, editors. Diabetes Mellitus: A Fundamental and Clinical Text. 2nd ed. Philadelphia, PA: Lippincott, Williams and Wilkins: 2000.

2. Vinik AI, Suwanwalaikorn S. Autonomic neuropathy. In: DeFronzo RA, editor. Current Therapy of Diabetes Mellitus. St Louis MO: Mosby; 1997.

3. Vinik AI, Erbas T, Park TS. Methods for evaluation of peripheral neurovascular dysfunction. Diabetes Technol Ther. 2001;3:29-50.

4. Vinik A, Pittenger G, Anderson A, Stansberry K, McNear E, Barlow P. Topiramate improves C-fiber neuropathy and features of the dysmetabolic syndrome in Type 2 diabetes. Diabetes. 2003;52 Suppl 1:A130.

5. Goldstein DJ, Lu Y, Detke MJ, Lee TC, Iyengar S. Duloxetine vs placebo in patients with painful diabetic neuropathy. Pain. 2005;116: 109-118.

6. Rosenstock J, Tuchman M, LaMoreaux L, Sharma U. Pregabalin for the treatment of painful diabetic peripheral neuropathy: A double-blind, placebo-controlled trial. Pain. 2004;110:628-638.

7. Raskin P, Donofrio PD, Rosenthal NR, et al. Topiramate vs placebo in painful diabetic neuropathy: Analgesic and metabolic effects. Neurology. 2004;63:865-873.

8. Ben Menachem E, Axelsen M, Johanson EH, Stagge A, Smith U. Predictors of weight loss in adults with topiramate-treated epilepsy. Obes Res. 2003;11:556-562.

9. Mehra S, Tavakoli M, Kallinikos PA, et al. Corneal confocal microscopy detects early nerve regeneration after pancreas transplantation in patients with type 1 diabetes. Diabetes Care. 2007;30:2608-2612.

10. Vinik EJ, Hayes RP, Oglesby A, et al. The development and validation of the Norfolk QOL-DN, a new measure of patients' perception of the effects of diabetes and diabetic neuropathy. Diabetes Technol Ther. 2005;7:497-508.

11. Stansberry KB. Primary nociceptive afferents mediate the blood flow dysfunction in non-glabrous (hairy) skin of type 2 diabetes. Diabetes Care. 1999;22:1549-1554.

12. Griffin JW, Hsieh ST, McArthur JC, Cornblath DR. Laboratory testing in peripheral nerve disease. Neurol Clin. 1996;14:119-133.

13. McCarthy BG, Hsieh ST, Stocks A, et al. Cutaneous innervation in sensory neuropathies: Evaluation by skin biopsy. Neurology. 1995;45: 1848-1855.

14. Kennedy WR, Said G. Sensory nerves in skin. Neurology. 1999;53: 1614-1615.

15. Periquet MI, Novak V, Collins MP, et al. Painful sensory neuropathy: Prospective evaluation using skin biopsy. Neurology. 1999;53: 1641-1647.

16. Pittenger GL, Ray M, Burcus NI, McNulty P, Basta B, Vinik AI. Intraepidermal nerve fibers are indicators of small-fiber neuropathy in both diabetic and nondiabetic patients. Diabetes Care. 2004;27:1974-1979.

17. Vinik AI, Suwanwalaikorn S, Stansberry KB, Holland MT, McNitt PM, Colen LE. Quantitative measurement of cutaneous perception in diabetic neuropathy. Muscle Nerve. 1995;18:574-584.

18. Krishnan ST, Rayman G. The LDI flare: A novel test of C-fiber function demonstrates early neuropathy in type 2 diabetes. Diabetes Care. 2004;27:2930-2935.

19. Vinik AI, Erbas T, Park T, Stansberry KB, Pittenger G. Platelet and neurovascular dysfunction in diabetes mellitus. Diabetes Care. 2001; 24:1476-1485.

20. Stansberry KB, Hill MA, Shapiro SA, McNitt PM, Bhatt BA, Vinik AI. Impairment of peripheral blood flow responses in diabetes resembles an enhanced aging effect. Diabetes Care. 1997;20:1711-1716.

21. McArthur JC, Stocks EA, Hauer P, Cornblath DR, Griffin JW. Epidermal nerve fiber density: Normative reference range and diagnostic efficiency. Arch Neurol. 1998;55:1513-1520.

22. Kennedy W, Said G. Sensory nerves in skin: Answers about painful feet? Neurology. 1999;53:1614-1615. 
23. Dalsgaard CJ, Rydh M, Haegerstrand A. Cutaneous innervation in man visualized with protein gene product 9.5 (PGP 9.5) antibodies. Histochemistry. 1989;92:385-390.

24. Polydefkis M, Yiannoutsos CT, Cohen BA, et al. Reduced intraepiderma nerve fiber density in HIV-associated sensory neuropathy. Neurology. 2002;58:115-119.

25. Holland NR, Crawford TO, Hauer P. Small-fiber sensory neuropathies: Clinical course and neuropathology of idiopathic cases. Ann Neurol. 1998;44:47-59.

26. Petersen KL, Rice FL, Suess F, Berro M, Rowbotham MC. Relief of post-herpetic neuralgia by surgical removal of painful skin. Pain. 2002; 98:119-126.

27. Griffin JW, McArthur JC, Polydefkis M. Assessment of cutaneous innervation by skin biopsies. Curr Opin Neurol. 2001;14:655-659.

28. Kennedy WR, Wendelschafer-Crabb G, Johnson T. Quantitation of epidermal nerves in diabetic neuropathy. Neurology. 1996;47: 1042-1048.

29. Chien H, Tseng T, Lin W, et al. Quantitative pathology of cutaneous nerve terminal degeneration in the human skin. Acta Neuropathol. 2001; 102:455-461.

30. Pittenger G, Mehrabyan A, Simmons K, et al. Small fiber neuropathy is associated with the metabolic syndrome. Metab Syndr Relat Disord. 2005;3:113-121.

31. Lauria G, Lombardi R. Skin biopsy: A new tool for diagnosing peripheral neuropathy. BMJ. 2007;334:1159-1162.

32. Shun CT, Chang YC, Wu HP, et al. Skin denervation in type 2 diabetes: Correlations with diabetic duration and functional impairments. Brain. 2004;127(Pt 7):1593-1605.

33. Smith AG, Russell J, Feldman EL, et al. Lifestyle intervention for prediabetic neuropathy. Diabetes Care. 2006;29:1294-1299.

34. Dodgson SJ, Shank RP, Maryanoff BE. Topiramate as an inhibitor of carbonic anhydrase isoenzymes. Epilepsia. 2000;41 Suppl 1: S35-S39.

35. Zhang X, Velumian AA, Jones OT, Carlen PL. Modulation of high-voltage-activated calcium channels in dentate granule cells by topiramate. Epilepsia. 2001;41 Suppl 1:S52-S60.

36. Yang Y, Shuaib A, Muzaffar Q, Siddiqui M. Neuroprotection by delayed administration of topiramate in a rat model of middle cerebral artery embolization. Brain Res. 1998;804:169-176.

37. Lee SR, Kim SP, Kim JE. Protective effect of topiramate against hippocampal neuronal damage after global ischemia in the gerbils. Neurosci Lett. 2000;281:183-186.
38. Boulton AJ, Vinik AI, Arezzo JC, et al. Diabetic neuropathies: A statement by the American Diabetes Association. Diabetes Care. 2005;28:956-962.

39. Thienel U, Neto W, Schwabe SK, Vijapurkar U. Topiramate in painful diabetic polyneuropathy: Findings from three double-blind placebocontrolled trials. Acta Neurol Scand. 2004;110:221-231.

40. Donofrio PD, Raskin P, Rosenthal NR, et al. Safety and effectiveness of topiramate for the management of painful diabetic peripheral neuropathy in an open-label extension study. Clin Ther. 2005;27:1420-1431.

41. Dyck PJ. Detection, characterization and staging of polyneuropathy: Assessed in diabetes. Muscle Nerve. 1988;11:21-32.

42. Consensus Statement. Report and recommendations of the San Antonio conference on diabetic neuropathy. American Diabetes Association American Academy of Neurology. Diabetes Care. 1988;11:592-597.

43. Stansberry KB, Hill M, McNitt PM, Bhatt BA, Vinik AI. Skin blood flow reactivity and neuropathy. Diabetes. 1994;43 Suppl 1:107A.

44. Pittenger G, Simmons K, Anandacoomaraswamy D, Rice A, Barlow P, Vinik A. Topiramate improves intraepidermal nerve fiber morphology and quantitative neuropathy measures in diabetic neuropathy patients. J Peripher Nerv Syst. 2005;10 Suppl 1;73.

45. Sumner C, Sheth S, Griffin J, Cornblath D, Polydefkis M. The spectrum of neuropathy in diabetes and impaired glucose tolerance. Neurology. 2003;60:108-111.

46. Smith AG, Ramachandran P, Tripp S, Singleton JR. Epidermal nerve innervation in impaired glucose tolerance and diabetes-associated neuropathy. Neurology. 2001;57:1701-1704.

47. Pittenger G. Diabetic neuropathy induces N1E-115 neuroblastoma cell apoptosis: protective role of topiramate. Grant from RW Johnson Pharmaceutical Research Institute; 2004.

48. Edwards K, Glantz MJ, Button J. Efficacy and safety of topiramate in the treatment of painful diabetic neuropathy: A double-blind, placebocontrolled study. Neurology. 2000;54 Suppl 3:A81.

49. York DA, Singer L, Thomas S, Bray GA. Effect of topiramate on body weight and body composition of Osborne-Mendel rats fed a high-fat diet: Alterations in hormones, neuropeptide, and uncoupling-protein mRNAs. Nutrition. 2000;16:967-975.

50. Li Z, Maglione M, Tu W, et al. Meta-analysis: Pharmacologic treatment of obesity. Ann Intern Med. 2005;142:532-546.

51. Astrup A, Toubro S. Topiramate: A new potential pharmacological treatment for obesity. Obes Res. 2004;12 Suppl:S167-S173.

Diabetes, Metabolic Syndrome and Obesity: Targets and Therapy

Dovepress

\section{Publish your work in this journal}

Diabetes, Metabolic Syndrome and Obesity: Targets and Therapy is an international, peer-reviewed open-access journal committed to the rapid publication of the latest laboratory and clinical findings in the fields of diabetes, metabolic syndrome and obesity research. Original research, review, case reports, hypothesis formation, expert opinion and commentaries are all considered for publication. The manuscript management system is completely online and includes a very quick and fair peer-review system, which is all easy to use. Visit http://www.dovepress.com/testimonials.php to read real quotes from published authors. 